\title{
THE CALORIMETRIC DETERMINATION OF THE IN- TRINSIC ENERGY OF GASES AS A FUNCTION OF THE PRESSURE. DATA ON OXYGEN AND ITS MIXTURES WITH CARBON DIOXIDE TO 40 ATMOSPHERES AT $28^{\circ} \mathrm{C}$.
}

\author{
By Frederick D. Rossini and Mikkel Frandsen
}

\section{ABSTRACT}

The intrinsic or internal energy, $U$, of air, oxygen, and mixtures of oxygen and carbon dioxide (to 37 mole per cent), has been determined calorimetrically as a function of the pressure, to 40 atmospheres, at $28^{\circ} \mathrm{C}$.

Within the limits of error of the measurements, $(\partial U / \partial p)_{T}$ is constant over the given range; and its values for the different gases, at $28^{\circ}$ C., 0 to 40 atmospheres, in joules per atmosphere per mole, are: Air, -6.08; oxygen, $-6.51 ; 0.075$ carbon dioxide and 0.925 oxygen, $-7.41 ; 0.175$ carbon dioxide and 0.825 oxygen, -8.74 ; 0.231 carbon dioxide and 0.769 oxygen, $-9.58 ; 0.366$ carbon dioxide and 0.634 oxygen, -12.04 . These values are estimated to be accurate within $\pm 21 / 2$ per cent. The data on the mixtures of oxygen and carbon dioxide can be represented by the equation $(\partial U / \partial p)_{301}{ }^{\circ} \mathrm{K} .=-6.51-11.0 x-11.0 x^{2}$, where $x$ is the mole fraction of carbon dioxide. The value of $(\partial U / \partial p)_{T}$ for air, oxygen, and the mixtures of oxygen and carbon dioxide at other near temperatures can be computed by means of the temperature coefficient of $(\partial U / \partial p)_{T}$ given by Washburn, namely, -0.4 per cent per degree.

\section{CONTENTS}

Page

I. Introduction

II. Method....... 733

III. Apparatus

IV. Procedure

V. Examination of the gases

VI. Analysis of the measured quantities... 739

VII. Units and auxiliary data

VIII. Experimental data

IX. Results of the present investigation

$X$. Comparison of the present results with values computed from other data

XI. Acknowledgment. 747

\section{INTRODUCTION}

The theory of determining calorimetrically the intrinsic or internal energy of gases as a function of the pressure has been given in a preceding paper by Washburn." The present paper reports the results of experiments on air, oxygen, and mixtures of oxygen and carbon dioxide (to 36.6 mole per cent), to a pressure of about 40 atmospheres, at $28^{\circ} \mathrm{C}$.

\section{METHOD}

The method employed in these experiments is as follows:

A mass, $m$, of gas is compressed in a bomb to a pressure of $p$ atmospheres. 
The bomb with its charge of gas is placed in a calorimeter at the temperature, $T$.

When the entire system has attained the temperature $T$, the gas is allowed to escape from the bomb to the atmosphere through a coil of tubing immersed in the calorimeter water. At the same time electrical energy is introduced into the calorimeter at such a rate as to maintain the temperature of the calorimeter sensibly constant at $T$. The amount of the electrical energy will be equal to the work done by the gas as it pushes back the atmosphere plus the change in internal energy which the gas undergoes as it drops from the pressure $p$ to the atmospheric pressure $B$.

The work done by the gas as it emerges from the bomb is

$$
W=n(B v)_{1 \mathrm{~atm} .}-B v_{b}
$$

where $n$ is the number of moles of the gas; $(B v)_{1 \mathrm{~atm}}$. is the product of the pressure and volume for 1 mole of the gas at the temperature $T$ and the pressure $B$ (practically 1 atmosphere) $: v_{b}$ is the internal volume of the bomb at the atmospheric pressure $B$.

The change in internal energy of the gas is, per mole;

$$
\Delta U]_{p}^{B}=U_{B}-U_{p}
$$

If the amount of electrical energy, $Q$, that is added maintains the temperature of the calorimeter constant at $T$, then

$$
Q=n \Delta U]_{p}^{B}+n(B v)_{1 \text { atm } .}-B v_{0}
$$

and

$$
\Delta U]_{p}^{B}+(B v)_{1 \text { atm } .}=\frac{Q+B v_{\imath}}{n}
$$

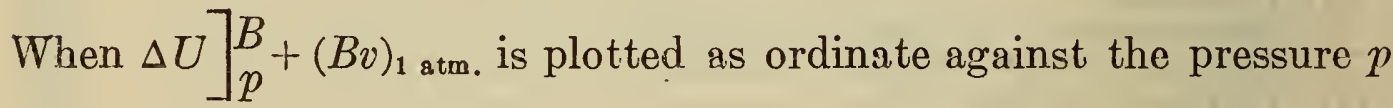
as abscissa, the curve, at $p=1$, will pass through the value of $(B v)_{1 \text { atm., }}$, which is constant and known for the given gas. And the slope of the curve will give the value of $-(\partial U / \partial p)_{T}$ for the gas.

Because of the fact that the steel of the bomb is not an incompressible substance having a zero temperature coefficient of expansion ${ }^{2}$ and because the temperature may not remain absolutely constant, several small corrections to equation (4) need be added.

1. The ideal experiment is one in which the temperature of the calorimeter remains absolutely constant at the initial temperature $T$ throughout the experiment. Actually, the temperature changed by a small amount, $\Delta t_{\text {corr. }}$ and the gas left the calorimeter at some average value $T_{g}\left(T_{0}-T\right.$ is about $0.01^{\circ} \mathrm{C}$.). The energy required to raise the temperature of the calorimeter from $T$ to $T+\Delta t_{\mathrm{corr}}$ is equal to the product of $\Delta t_{\text {corr. }}$ and $C_{p \text { (calor.) }}$, the heat capacity of the calorimeter. The energy required to raise the temperature of the gas from $T$ to $T_{a}$ is equal to $C_{p \text { (gas) }}\left(T_{o}-T\right)$. The temperature of the issuing gas at any instant was assumed to be that of the calorimeter. 
2. There is a change in the intrinsic energy of the steel bomb itself as the pressure within it changes from $p$ to $B$ atmospheres. This amount of energy is calculable thermodynamically ${ }^{3}$ according to the formula

$$
\left(\frac{\partial U_{b}}{\partial p}\right)_{T}=-T\left(\frac{\partial v}{\partial T}\right)_{p}-(p-1)\left(\frac{\partial v}{\partial p}\right)_{T}
$$

For the bomb used in the present experiments

$$
\begin{gathered}
v=1.014 \mathrm{l} \\
\frac{1}{v}\left(\frac{\partial v}{\partial T}\right)_{p}=33 \times 10^{-6} \quad{ }^{\circ} \mathrm{C} .^{-1} \\
\left(\frac{\partial v}{\partial p}\right)_{T}=39 \times 10^{-6} \mathrm{latm}^{-1}
\end{gathered}
$$

Then, at $28^{\circ} \mathrm{C}$., the bomb energy, for a drop in pressure from $p$ to 1 atmosphere, is

$$
\left.-\Delta U_{b}\right]_{\frac{1}{p}}^{1}=1.02(p-1)+0.002(p-1)^{2} \text { joules }
$$

Equation (9) gives the values shown in Table 1.

At 40 atmospheres, the value of $\left.\Delta U_{b}\right]_{p}^{1}$ is about 10 per cent of the value of $n \Delta U]_{-}^{1}$ for air, and about 5 per cent of that for the mixture of 0.634 oxygen and 0.366 carbon dioxide. The uncertainty in the value used for the bomb energy is estimated to be \pm 10 per cent of itself, or one-half to 1 per cent of the value of $n \Delta U]_{p}^{1}$ for the gases in the experiments at 40 atmospheres.

3. The opening of the valve to let the compressed gas escape from the bomb resulted in the transfer of energy to the calorimeter through friction of the stem on the seat of the valve. This amount of energy was found by measurement to be

$$
e=1.5 \pm 0.5 \text {-joules }
$$

For the present experiments, then

$$
\Delta U]_{p}^{B}+(B v)_{1 \text { atm. }}=\frac{Q+B v_{b}-C_{p \text { (calor.) }}\left(\Delta t_{\text {corr. }}\right)-C_{p \text { (gas) }}\left(T_{q}-T\right)+E}{n}
$$

The value of $E$ in equation (11) is given by the sum of equations (9) and (10):

$$
E=1.02(p-1)+0.002(p-1)^{2}+1.5 \text { joules }
$$

The temperature of the experiment was taken as $T_{g}$. 
TABLE 1

\begin{tabular}{|c|c|}
\hline$p$ & $\left.-\Delta U_{b}\right]_{p}^{1}$ \\
\hline Atmospheres & Joules \\
10 & 9.3 \\
20 & 20.1 \\
30 & 31.3 \\
40 & 42.8 \\
\hline
\end{tabular}

\section{APPARATUS}

The calorimeter, thermometric system, energy measuring devices, etc., were the same as those used in previous investigations ${ }^{4}$ with the exception that a more sensitive galvanometer was used with the Mueller bridge and platinum resistance thermometer.

The steel bomb used in the present investigation is shown in place in the calorimeter can in Figure 1. Here $A$ is the calorimeter can; $B$, the steel bomb; $C$, the copper coil through which the gas passed before leaving the calorimeter; $D$, the electrical resistance heater; $E$, the platinum resistance thermometer; $F$, the glass tube at the exit end of the copper coil; $G$, the valve; $H$ and $I$, wrenches for opening the valve; $J$, the cover of the calorimeter can; $K$, the current leads.

The heating coil ( $D$, fig. 1 ) was made by winding enameled constantan wire (No. 30, B. and S. gage) noninductively over mica on a piece of sheet copper made in the form of an inverted trough with open ends. Current leads of enameled copper (No. 24, B. and S. gage) were soldered to the ends of the constantan wire, and the whole was covered with a thin layer of "Pizein" cement. The heater, which had a resistance of about $22 \mathrm{ohms}$, was placed in position over the fitting which joined the copper coil to the valve of the bomb. Potential leads of enameled copper (No. 28, B. and S. gage) were soldered to the current leads at a point midway between the calorimeter and the jacket, with which all four leads were in good thermal contact.

The bomb, which was tested to 65 atmospheres, had a wall thickness of $1.65 \mathrm{~mm}$; a mass, with valve, of $745 \mathrm{~g}$; a diameter of $10 \mathrm{~cm}$; a height of $16 \mathrm{~cm}$; an internal volume of $1,014 \mathrm{~cm}^{3}$; and was made of a low carbon (0.12 per cent) steel. The copper coil, whose mass was $1,004 \mathrm{~g}$, was made up of a total length of about 40 feet of $1 / 8,3 / 16$, and $1 / 4$ inch copper tubing.

The assembly of the apparatus used in filling the bomb and for determining the temperature and pressure of the gas in the charged bomb is shown in Figure 2: $A$ is the storage cylinder; $B$ is a heavy steel purifying tube, which contained "ascarite" (sodium hydroxideasbestos mixture) and "dehydrite" $\left(\mathrm{Mg}\left(\mathrm{ClO}_{4}\right)_{2} \cdot 3 \mathrm{H}_{2} \mathrm{O}\right)$ for the experiments on air and oxygen, and "dehydrite" alone for the experiments on the mixtures of oxygen and carbon dioxide; $C$ is a Bourdon gage for reading the pressure; $D$ is the steel bomb; $E$ is a glass jar contining water; and $F$ is the thermometer for reading the temperature. The connecting tubes were made of $7 / 8$-inch copper tubing.

4 Rossini, F. D., B. S. Jour. Research, vol. 6 (RP259), p. 1, 1931. 


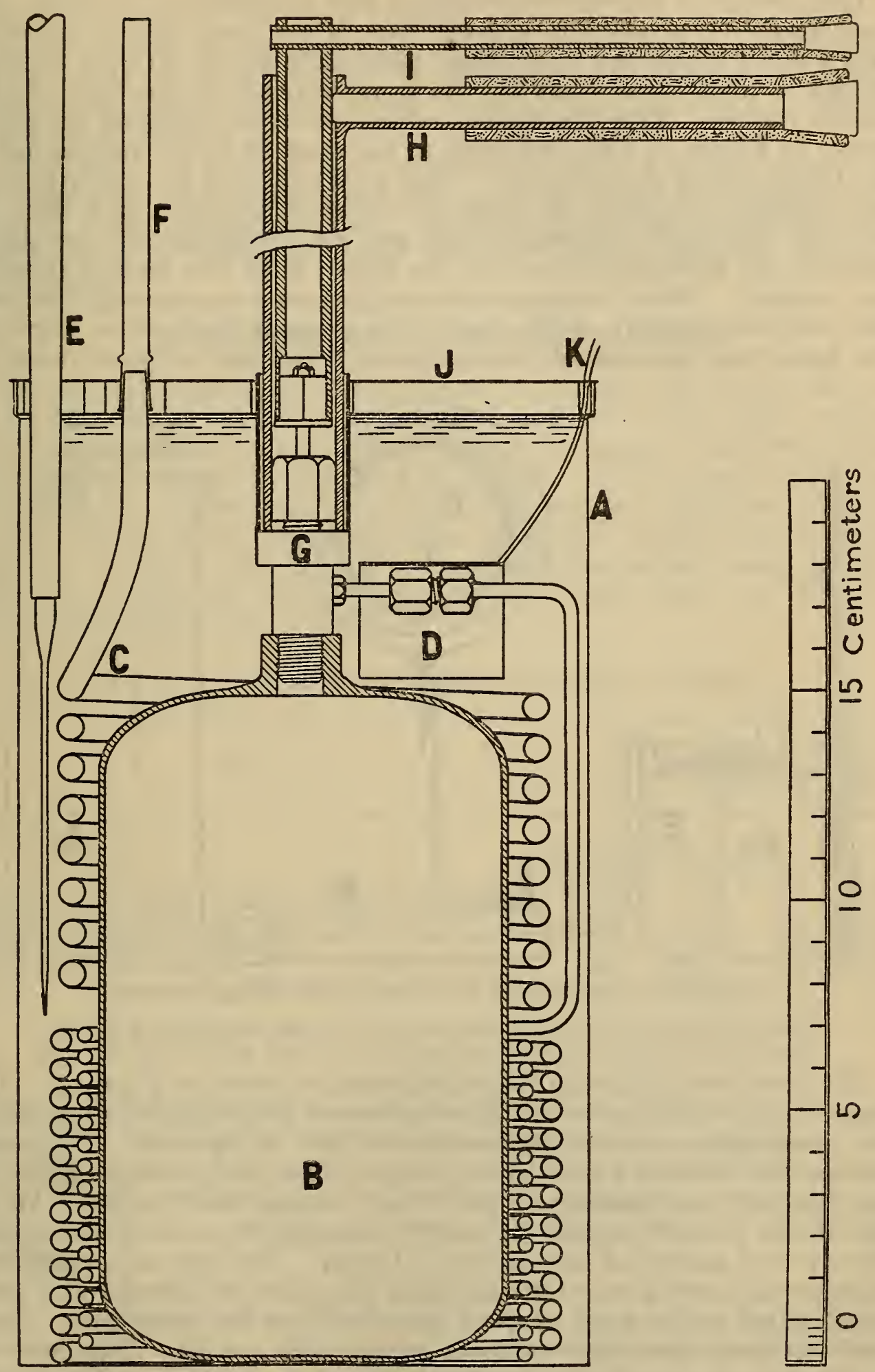

FIGURE 1.-Assembly of the bomb and the calorimeter can

The various parts of the assembly, which are drawn to scale, are described in the text 


\section{PROCEDURE}

The procedure for each experiment was as follows: The bomb was evacuated to a pressure of about $2 \mathrm{~mm}$ of mercury, closed, wiped off with a cloth moistened with ether, allowed to dry in air, and weighed against a counterpoise having the same volume as the bomb and a similar surface. Then the bomb was connected to the filling apparatus shown in Figure 2, and immersed to the neck in water maintained at the temperature of the room. The purifying and connecting tubes were flushed out with gas from the storage cylinder, and then the valve of the bomb was opened and gas was permitted to flow slowly through the purifying tube into the bomb until the desired pressure was reached. When temperature equilibrium was attained, the pressure and temperature of the gas in the charged bomb were recorded. The bomb was then closed, disconnected, dried, and weighed as before.

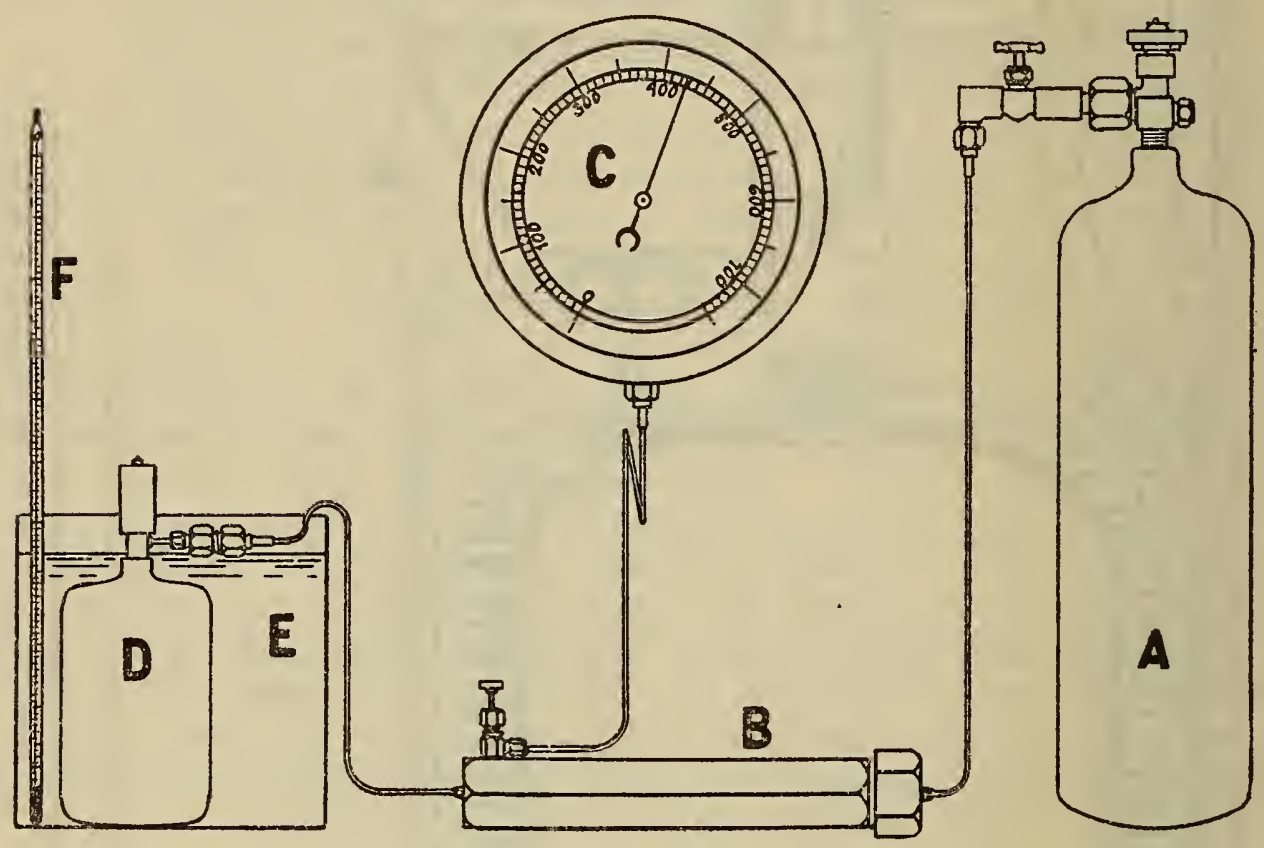

FigURE 2.-Apparatus and bomb for the filling operation

The various parts of the assembly, which are drawn to scale, are described in the text.

The bomb was placed in the calorimeter as shown in Figure 1. The temperature of the jacket of the calorimeter was maintained constant at a temperature several degrees above that of the room. The calorimeter was brought to the jacket temperature, and, when equilibrium was reached, the readings of the "fore" period were begun. At the end of the "fore" period (10 to 20 minutes) the valve was opened slightly and electrical heating was started. The gas was permitted to escape at such a rate that the heat absorbed by the gas was practically equal to the heat evolved electrically in the same time. At a predetermined time the electrical energy was cut off. Temperature equilibrium was established in 5 to 10 minutes and the readings of the "after" period were begun. The lengths of the "fore," "reaction," and "after" periods were usually the same.

After one or two experiments on a given gas it was usually possible to so gage the rate of input of the electrical energy that the net change in the temperature of the calorimeter was not more than $0.01^{\circ} \mathrm{C}$. 
Readings of the calorimeter temperature, the current, and the voltage were taken every minute and of the jacket temperature every two minutes during the "reaction" period.

The true mass of the gas in the charged bomb was computed from the apparent increase in weight of the bomb, the residual gas in the bomb before charging (several $\mathrm{mg}$ ) and the buoyant effect of the air on the brass weights.

The pressure of the gas in the charged bomb at the temperature of the calorimetric experiment was computed by correcting the observed pressure $p^{\prime}$ at the temperature $T^{\prime}$ to the calorimetric temperature $T_{\mathrm{g}}$ by means of the perfect gas law, $T^{\prime}$ and $T_{\mathrm{g}}$ being the same within a few degrees.

\section{EXAMINATION OF THE GASES}

The air and oxygen and the mixtures of oxygen and carbon dioxide were respectively examined for oxygen and for oxygen and carbon dioxide, and the density of the inert gas in the oxygen was determined by the gas chemistry section of this bureau. The average molecular weights of the oxygen and the mixtures of oxygen and carbon dioxide were computed from the percentages of oxygen, carbon dioxide, and inert gas present, and from their separate molecular weights-the molecular weight of the inert gas being known from its density. These results are given in Table 2.

TABLE 2.-Composition and molecular weights of the gases

\begin{tabular}{|c|c|c|c|c|}
\hline Gas & $\mathrm{O}_{2}$ & $\mathrm{CO}_{2}$ & ${ }_{\text {gases }}^{N_{2}+\text { rare }}$ & $\begin{array}{c}\text { Molecu- } \\
\text { lar } \\
\text { weight }\end{array}$ \\
\hline 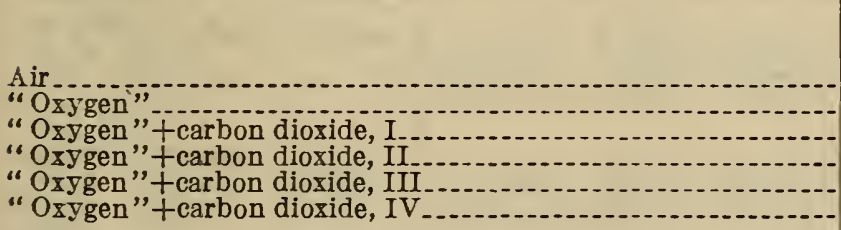 & $\begin{array}{r}\text { Mole } \\
\text { per cent } \\
20.99 \\
99.41 \\
91.66 \\
81.71 \\
76.18 \\
62.80\end{array}$ & $\begin{array}{c}\text { Mole } \\
\text { per cent }\end{array}$ & $\begin{array}{r}\text { Mole } \\
\text { per cent } \\
79.01 \\
.59 \\
.82 \\
.84 \\
.78 \\
.60\end{array}$ & $\begin{array}{l}\text { 9. } \\
28.959 \\
32.012 \\
32.91 \\
34.11 \\
34.80 \\
36.40\end{array}$ \\
\hline
\end{tabular}

\section{ANALYSIS OF THE MEASURED QUANTITIES}

The quantities involved in the calculation of the results of each experiment, exclusive of the corrections discussed in the latter part of Section II are the mass, pressure, and temperature of the gas in the bomb, the temperature change of the calorimeter, the electrical energy input, the atmospheric pressure, and the internal volume of the bomb.

In Table 3 are given, for the experiments on oxygen at 40 atmospheres, the magnitudes of the various quantities, the sensitivity of the measuring devices with respect to these quantities, and the "allowable error" in each that would contribute an absolute error of 1 joule to the result of each experiment. 
TABLE 3.-Analysis of the measured quantities

[For an experiment on oxygen at 40 atmospheres]

\begin{tabular}{|c|c|c|c|c|}
\hline 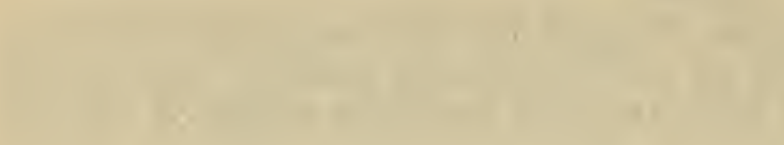 & $\begin{array}{l}\text { Magni- } \\
\text { tude of } \\
\text { the quan- } \\
\text { tity }\end{array}$ & $\begin{array}{l}\text { Sensitiv- } \\
\text { ity of the } \\
\text { measur- } \\
\text { ing de- } \\
\text { vice }\end{array}$ & $\begin{array}{l}\text { "Allow- } \\
\text { able er- } \\
\text { ror" in } \\
\text { the quan- } \\
\text { tity }\end{array}$ & Unit \\
\hline $\begin{array}{l}\text { Mass of gas } \\
\text { Pressure of gas } \\
\text { Temperature of gas. } \\
{ }_{\Delta} t_{\text {corr }}\end{array}$ & $\begin{array}{c}55 \\
40 \\
300 \\
4,700 \\
1 \\
1\end{array}$ & $\begin{array}{l}0.003 \\
.04 \\
.01 \\
.00002 \\
.2 \\
.001 \\
.001\end{array}$ & $\begin{array}{l}0.012 \\
.08 \\
.08 \\
.0001 \\
1 \\
.01 \\
.01\end{array}$ & $\begin{array}{l}\text { Gram. } \\
\text { Atmosphere. } \\
\text { o } \mathrm{K} \text {. } \\
{ }^{\circ} \mathrm{C} \text {. } \\
\text { Joule. } \\
\text { Atmosphere. } \\
\text { Liter. }\end{array}$ \\
\hline
\end{tabular}

\section{UNITS AND AUXILIARY DATA}

The unit of energy employed in the present work is the international joule.

For computing the value of the product of the pressure and volume for 1 mole of air, oxygen, and carbon dioxide at $28^{\circ} \mathrm{C}$. and 1 atmosphere, the following equation was used:

$$
(B v)_{1 \text { atm., } 28{ }^{\circ} \mathrm{C} .}=R T_{0}{ }^{\circ} \mathrm{C} .\left(1+28 \alpha_{28}{ }^{\circ} \mathrm{C} .\right)\left(1-\lambda_{0}{ }^{\circ} \mathrm{C} .\right)
$$

$R$ was taken as 8.3115 international joules degree ${ }^{-1}$ mole $^{-1}$, and $T_{0^{\circ} \mathrm{C} .}=273.10^{\circ} \mathrm{K}$. The values of the constants ${ }^{5}$ for air, oxygen, and

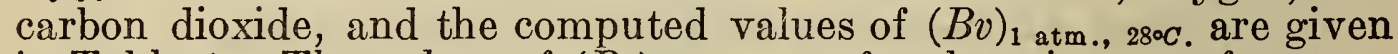
in Table 4. The values of $(B v)_{1 \mathrm{~atm} .}{ }_{28 \circ \mathrm{C}}$. for the mixtures of oxygen and carbon dioxide were obtained by interpolation.

TABLE 4.-Values of $\alpha_{28^{\circ}} \mathrm{C}, \lambda_{0}{ }^{\circ} \mathrm{C}$, and $(B v)_{1 \text { atm., }}{ }^{\circ}{ }^{\circ} \mathrm{C}$.

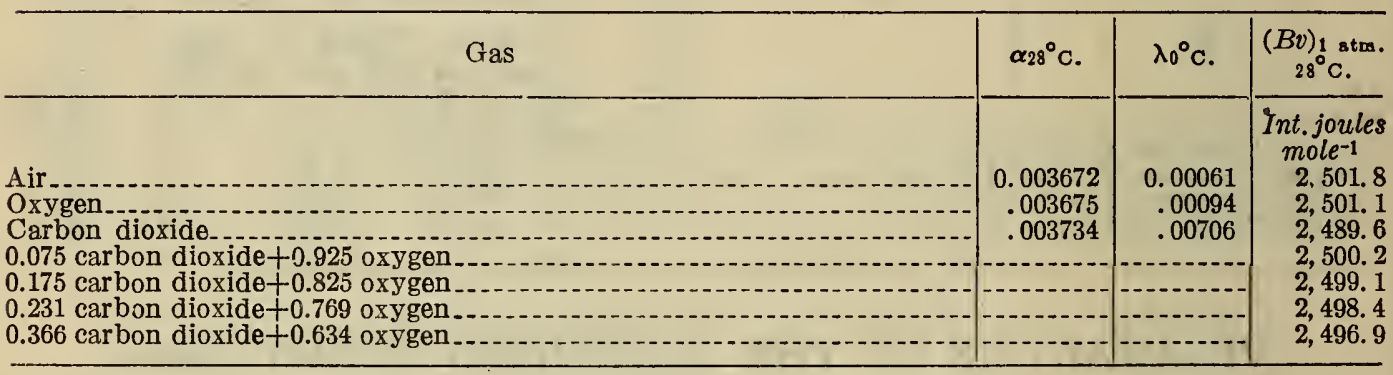

\section{EXPERIMENTAL DATA}

The experimental data obtained in the present experiments are given in Tables 5 and 6 . The column headings give the following information: Column 5, the pressure in the bomb $+(1-B)$, giving the initial pressure in the bomb corresponding to a final pressure of exactly 1 atmosphere; $6, T_{0}$ the average temperature at which the gas issued from the calorimeter, which is taken as the temperature of the experiment; 13 , the value of $E$, as given by equation $(12) ; 15$, a term which corrects the value of $\Delta U]_{p}^{1}$ from $T_{o}$ to $28^{\circ} \mathrm{C}$. (computed according to the formula given by Washburn $\left.{ }^{6}\right) ; 17$, the value of $\left.(B v)_{1 \text { atm. }}+\Delta U\right]_{p}^{1}$ for $28^{\circ} \mathrm{C}$.

S International Critical Tables, vol. 3, pp. 9, 10, 13. McGraw-Hill Book Co., New York, 1928,

- See footnote $1, \mathrm{p} .733$. In the last term of that formula $6 c T^{3}$ should read $6 c / T^{3}$, 


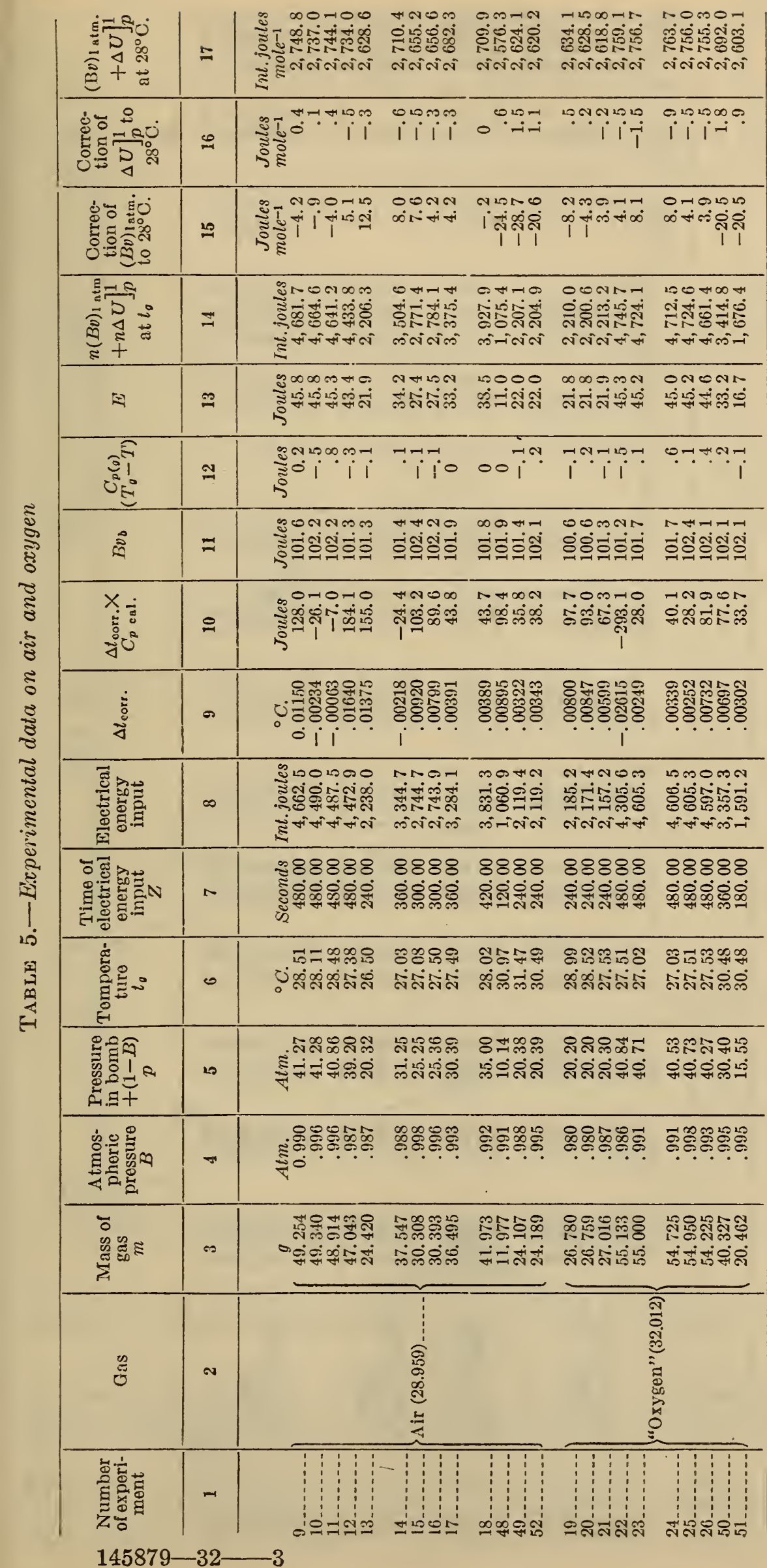




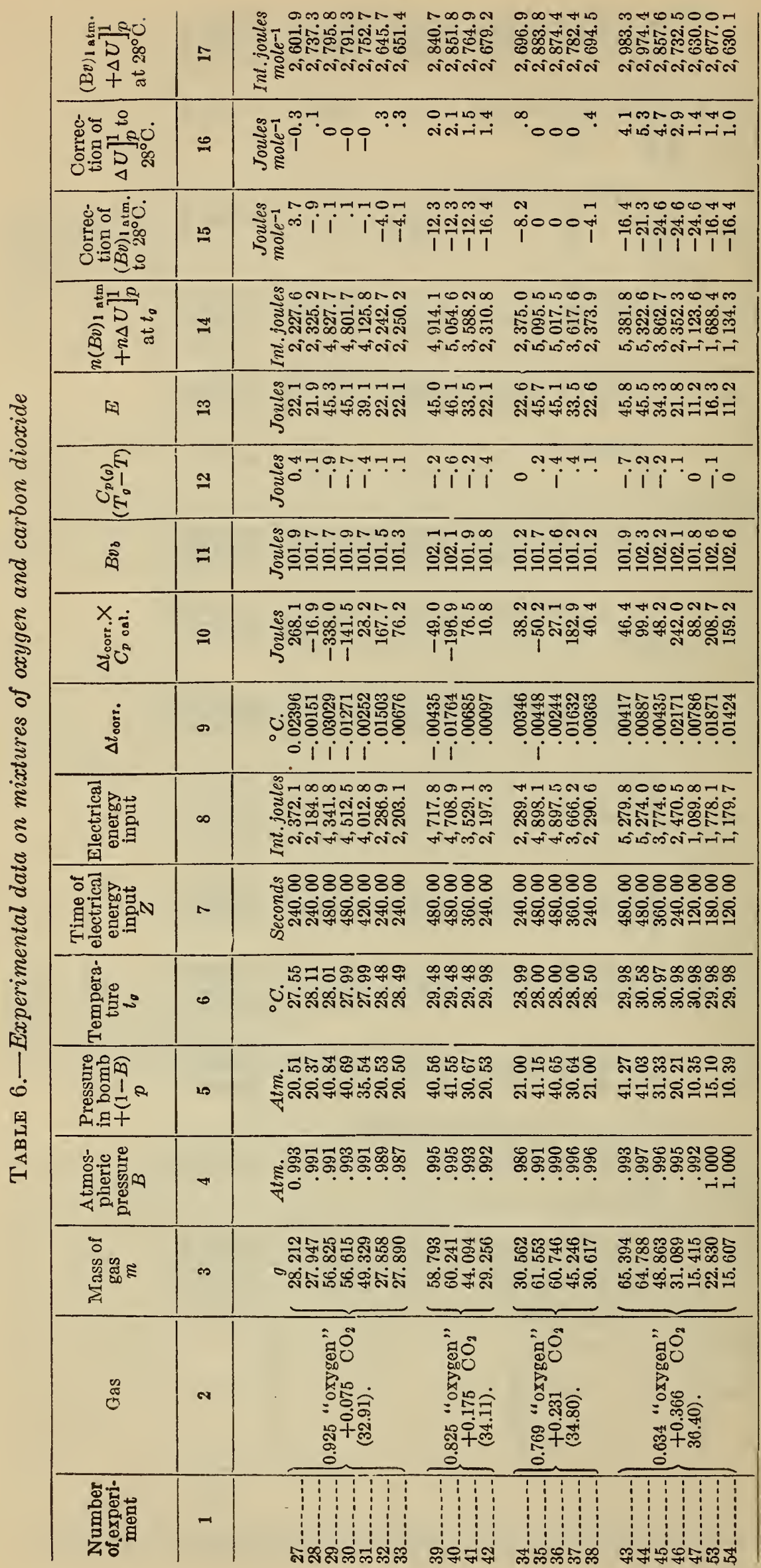




\section{RESULTS OF THE PRESENT INVESTIGATION}

The values of $\Delta U]_{p}^{1}+(B v)_{1}$ atm. that are given in Tables 5 and 6 were plotted against the pressure $p$; and the experimental values

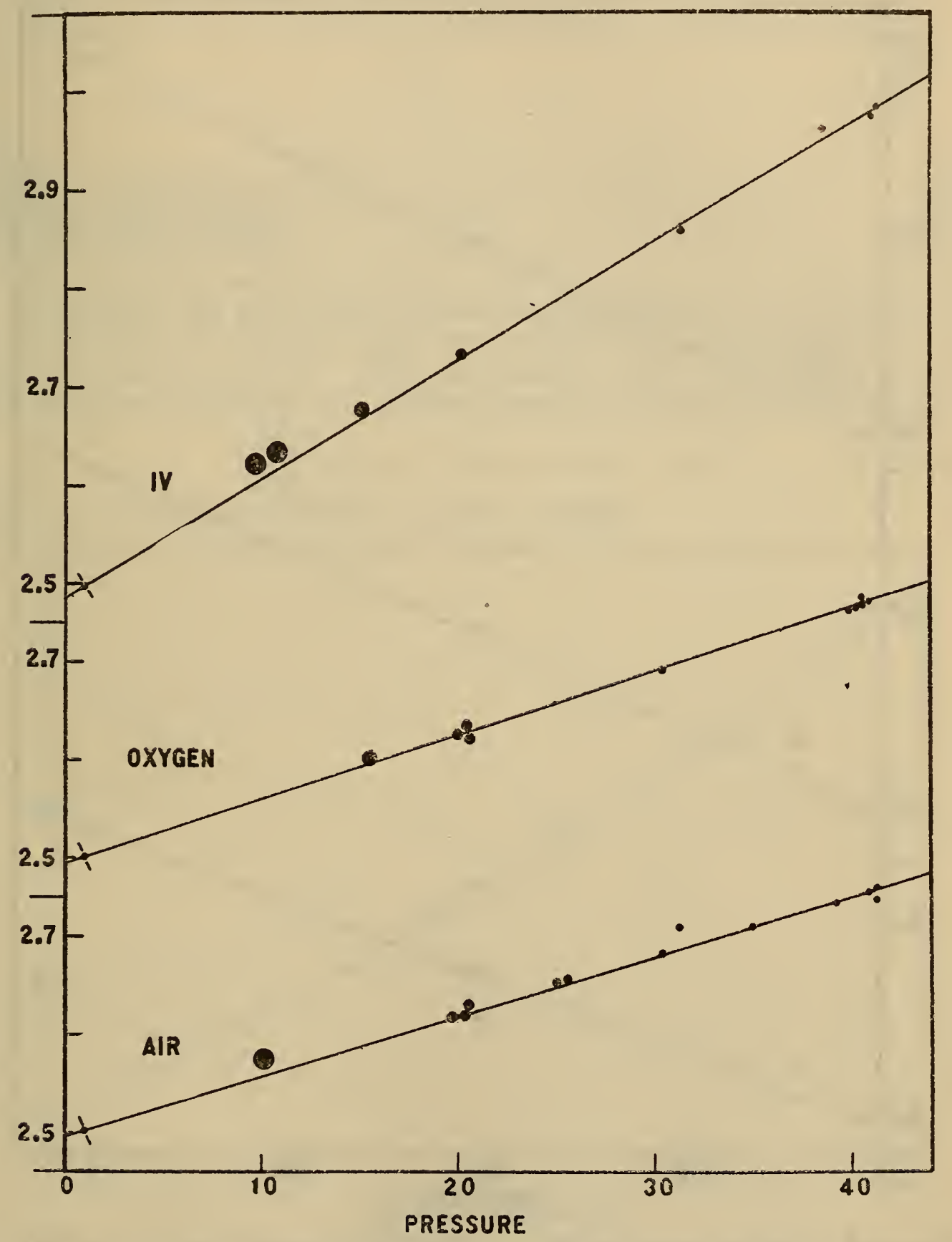

FIGURE 3. - Plot of the values of $\left.(B v)_{1 \text { arm. }}+\Delta U\right]_{p}^{1}$ for air, oxygen, and mixture $I V$, at $28^{\circ} \mathrm{C}$.

The scale of ordinates gives the value of $(B v)_{1}$ stm. $\left.+\Delta U\right]_{p}^{1}$ for ais, oxygen, and mixture IV (0.366 carbon dioxide and 0.634 oxygen) at $28^{\circ} \mathrm{C}$. in international kilojoules mole $e^{-1}$. The scale of abscissas gives the pressure in atmospheres.

and the resulting curves are shown in Figures 3 and 4. The points at $p=1$ are the values of $(B v)_{1 \mathrm{stm}}$. computed according to equation (13) and given in Table 4. In each case the experimental points 
are drawn with a radius that is equivalent to an error of 4 joules per experiment, which value, for the experiments on oxygen at 40 atmospheres, is 1 per cent of the value of $n \Delta U]_{p}^{1}$.

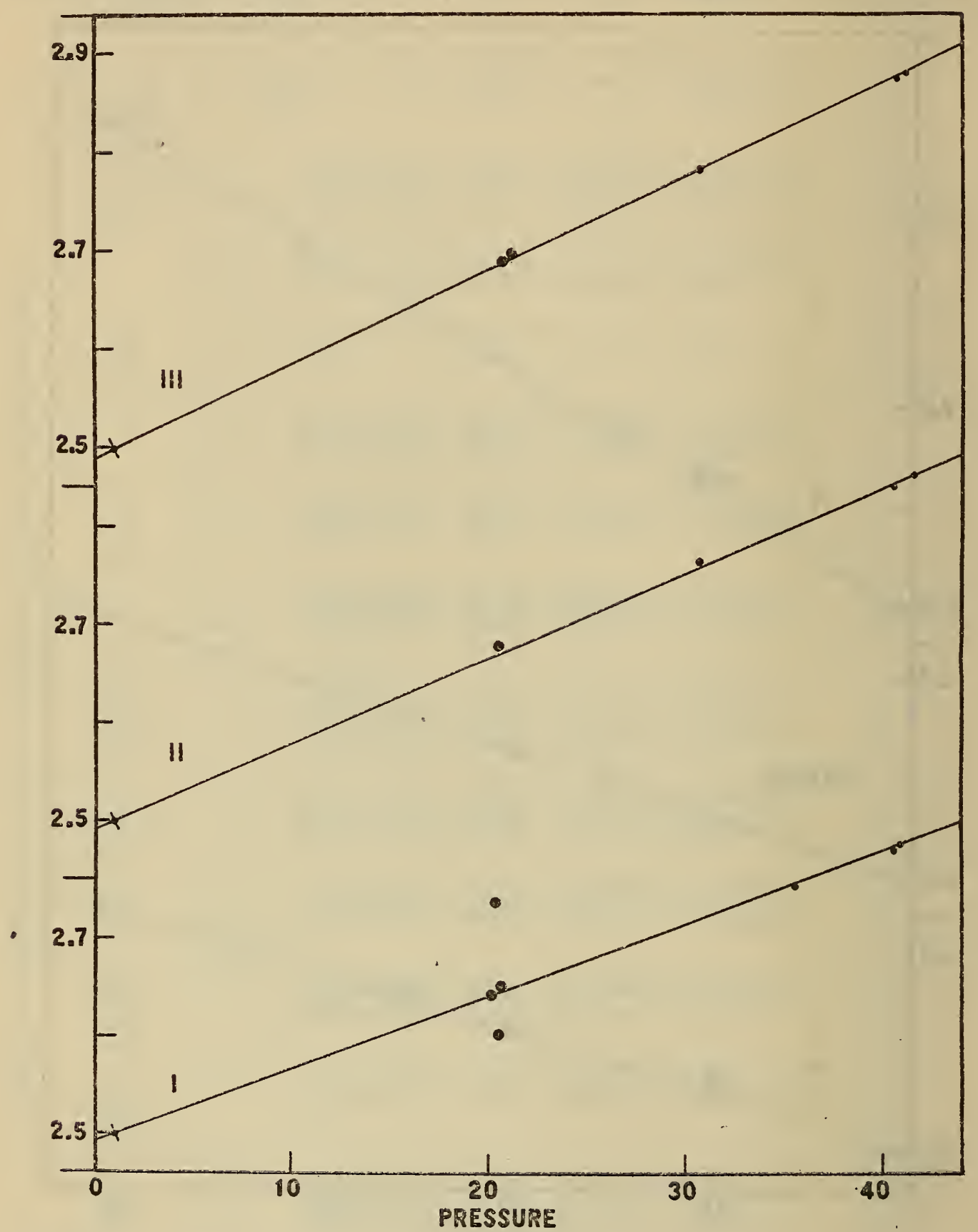

FIGURE 4.-Plot of the values $\left.(B v)_{1 \text { atm }}+\Delta U\right]_{p}^{1}$ for mixtures $I, I I$, and III of oxygen and carbon dioxide, at $28^{\circ} \mathrm{C}$.

The scale of ordinates gives the value of $(B v)_{1}$ atm $\left.+\Delta U\right]_{p}^{1}$ for mixture $\mathrm{I}$ ( 0.075 carbon dioxide and 0.925 oxygen), mixture II ( 0.175 carbon dioxide and 0.825 oxygen), and mixture III ( 0.231 carbon dioxide and 0.769 oxygen), at $28^{\circ} \mathrm{C}$. in international kilojoules mole ${ }^{-1}$. 'The scale of abscissas gives the pressure in
atmospheres.

Within the limits of error of the measurements, $\Delta U]_{p}^{1}$ is a linear function of the pressure up to 40 atmospheres, and consequently 
the value of $(\partial U / \partial p)_{T}$ is constant. The values of $(\partial U / \partial p)_{T}$ for the various gases, at $28^{\circ} \mathrm{C}$., 0 to 40 atmospheres, in joules per atmosphere per mole, are given in Table 7 . These values are estimated to be accurate within $\pm 2 \frac{1}{2}$ per cent.

TABLE 7.-Experimental values of $(\partial U / \partial p)_{T}$ at $28^{\circ} \mathrm{C} ., 0$ to 40 atmospheres

\begin{tabular}{|c|c|}
\hline Gas & $\begin{array}{l}\text { Joules } \\
\text { atm-1 } \\
\text { mole-1 }\end{array}$ \\
\hline $\begin{array}{l}\text { Air } \\
\text { Oxygen } \\
0.075 \text { carbon dioxide }+0.925 \text { oxygen } \\
0.175 \text { carbon dioxide }+0.825 \text { oxygen } \\
0.231 \text { carbon dioxide }+0.769 \text { oxygen } \\
0.366 \text { carbon dioxide }+0.634 \text { oxygen }\end{array}$ & $\begin{array}{l}-6.08 \\
-6.51 \\
-7.41 \\
-8.74 \\
-9.58 \\
-12.04\end{array}$ \\
\hline
\end{tabular}

In Figure 5 are plotted the values of $(\partial U / \partial p)_{T}$, as a function of the mole fraction of carbon dioxide, for oxygen and the mixtures of oxy gen and carbon dioxide. The smoothed values of $(\partial U / \partial p)_{301}{ }^{\circ} k$. for the mixtures of oxygen and carbon dioxide are given by the equation

$$
\left(\frac{\partial U}{\partial p}\right)_{301}^{\circ}{ }_{\mathrm{K} \cdot}=-6.51-11.0 x-11.0 x^{2}
$$

where $x$ is the mole fraction of carbon dioxide.

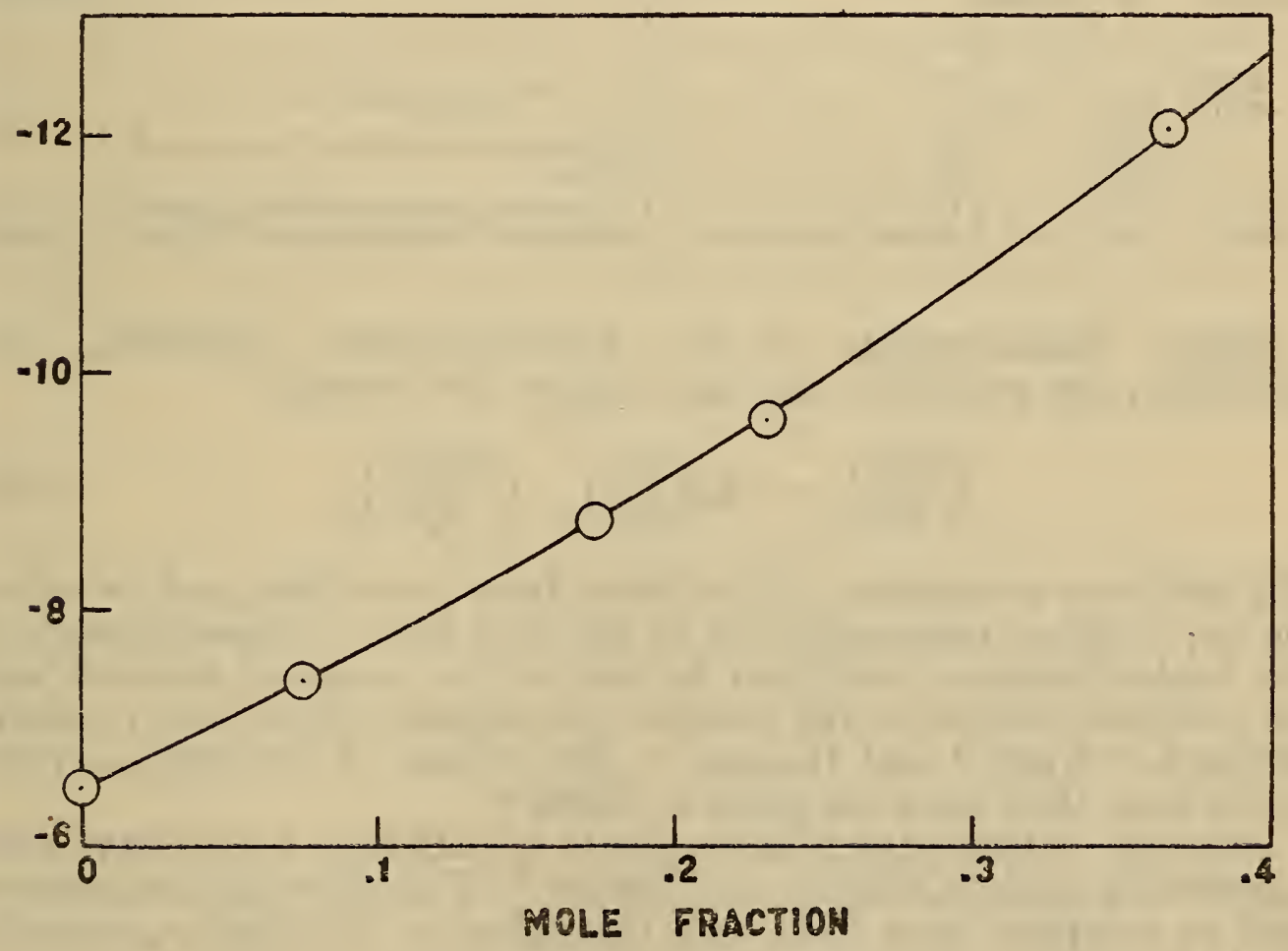

FIGURE 5. - Plot of the values of $(\partial U / \partial p)_{T}$ against the mole fraction of carbon dioxide, for mixtures of oxygen and carbon dioxide, at $28^{\circ} \mathrm{C}$.

The scale of ordinates gives the value of $(\partial U / \partial p) r$ at $28^{\circ} \mathrm{C}$. in joules atm $\mathrm{m}^{-1} \mathrm{~mole}^{-1}$. The scale of abscissas gives the mole fraction of carbon dioxide. The curve is represented by the equation, $(\partial U / \partial p)_{301}{ }^{\circ} \mathrm{K} .=-6.51-11.0 x-11.0 x^{2}$.

The values of $(\partial U / \partial p)_{T}$ for air, oxygen, and the mixtures of oxygen and carbon dioxide at other near temperatures can be computed by means of the temperature coefficient of $(\partial U / \partial p)_{T}$ given by Washburn $^{7}$, namely, -0.4 per cent per degree. 


\section{COMPARISON OF THE PRESENT RESULTS WITH VALUES COMPUTED FROM OTHER DATA}

Data similar to that reported in the present paper have not previously been obtained. Nevertheless, values of $(\partial U / \partial p)_{T}$ for some of the gases pertinent to the present work can be computed by means of the proper thermodynamic formulas from data on appropriate other properties.

Given adequate $p-v-T$ data, one can use the formula

$$
\left(\frac{\partial U}{\partial p}\right)_{T}=-T\left(\frac{\partial v}{\partial T}\right)_{p}-p\left(\frac{\partial v}{\partial p}\right)_{T}
$$

The $p-v-T$ data for nitrogen have been reviewed by Deming and Shupe ${ }^{8}$ and for nitrogen, air, and oxygen by Beattie and Bridgeman. ${ }^{9}$

From these data the values of $(\partial U / \partial p)_{301}{ }^{\circ} \mathrm{K}$ given in Table 8 have been computed for nitrogen, air, and oxygen.

TABLE 8. - Values of $(\partial U / \partial p)_{T}$ from various data

\begin{tabular}{|c|c|c|c|c|c|}
\hline \multicolumn{3}{|c|}{$\begin{array}{l}(\partial U / \partial p) 301^{\circ} \mathrm{k} .0 \text { to } 40 \text { atm. } \\
\text { (joules atm }-1 \text { mole-1 }\end{array}$} & \multirow{2}{*}{ Reference } & \multirow{2}{*}{ Kind of data } & \multirow{2}{*}{$\begin{array}{l}\text { Com- } \\
\text { puted by } \\
\text { means of } \\
\text { formula }\end{array}$} \\
\hline Nitrogen & Air & Oxygen & & & \\
\hline $\begin{array}{l}-5.82 \\
-5.97\end{array}$ & -5.82 & -6.65 & & $p-v-T$ measurements. & (15) \\
\hline 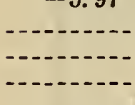 & $\begin{array}{l}-5.75 \\
-6.17 \\
-5.92 \\
-6.03\end{array}$ & & 12 & $\begin{array}{l}\text { Measurements of Joule-Thomson coeffi- } \\
\text { cient. }\end{array}$ & (16) \\
\hline$(-5.97)$ & $\begin{array}{l}-6.03 \\
-6.08\end{array}$ & -6.51 & Present investigation.-. & $\begin{array}{l}\text { Calorimetric measurements of }(\Delta H / \Delta p) T \text { - } \\
\text { Calorimetric measurements of }(\Delta U / \Delta p) T \text { - }\end{array}$ & $\begin{array}{l}\left.(17)^{(}\right) \\
(\partial U / \partial p)_{T}\end{array}$ \\
\hline
\end{tabular}

Where measurements of the Joule-Thomson coefficient, $\mu=$ $(\partial T / \partial p)_{H}$, are available, one can employ the formula

$$
\left(\frac{\partial U}{\partial p}\right)_{T}=-C_{p}\left(\frac{\partial T}{\partial p}\right)_{H}-\left(\frac{\partial(p v)}{\partial p}\right)_{T}
$$

The last term in equation (16) is taken from $p-v$ data, and its value, for air, is about one-tenth that of the first term. Measurements of the Joule-Thomson coefficient for air, in the range of pressure and temperature covered in the present investigation, have been made by Roebuck, ${ }^{11}$ Noell, ${ }^{12}$ and Hausen. ${ }^{13}$ The values of $(\partial U / \partial p)_{301^{\circ} \mathrm{K} . \mathrm{com}-}$ puted from their data are given in Table 8.

Recently, calorimetric measurements of $(\Delta H / \Delta p)_{T}$ for air have been reported by Eucken, Clusius, and Berger. ${ }^{14}$ The following formula was

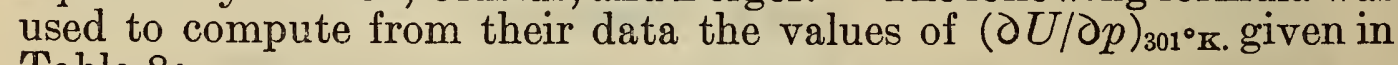
Table 8:

$$
\left(\frac{\partial U}{\partial p}\right)_{T}=\left(\frac{\partial H}{\partial p}\right)_{T}-\left(\frac{\partial(p v)}{\partial p}\right)_{T}
$$

\footnotetext{
${ }^{8}$ Deming, W. E., and Shupe, L. E., Phys. Rev., vol. 37, p. 638, 1931.

- Beattie, J. A., and Bridgeman, O.'C., J. Am. Chem. Soc., vol. 50, p. 3133, 1928.

$10 H=U+p v$.

11 Roebuck, J. R., Proc. Am. Acad. Arts Sci., vol. 60, p. 537, 1925.

12 Noell, F. Mitteilungen Forschungsarbeiten Gebiete Ingenienirwesens. No. 184, 1916. The data are taken from International Critical Tables, vol. 5, p. 144, McGraw-Hill Book Co., New York, 1929.

18 Hausen, H., Z. tech. Physik. vol. 7, pp. 371, 444, 1926.

14 Eucken, A., Clusius, K., and Berger, W., Z. tech. Physik. vol. 13, p. 267, 1932.
} 
In the bottom row of Table 8 are given the values of $(\partial U / \partial p)_{301^{\circ} \mathrm{K}}$. for air and oxygen as determined from the experiments of the present investigation. The value for nitrogen given in the bottom row was obtained by extrapolation from the values for oxygen and air, assuming the additivity of $(\partial U / p \partial)_{T}$ for the two components of air.

Inspection of Table 8 shows that, given an estimated error of $\pm 2 \frac{1}{2}$ per cent in each of the various values, all are in substantial agreement with the values obtained in the present investigation.

\section{ACKNOWLEDGMENT}

The authors acknowledge the technical advice of E. W. Washburn, under whose direction this investigation was carried out.

Washington, October 1, 1932. 